\title{
Editorial: Innovative Technology and System Integration for Gaseous Biofuels Production
}

\begin{abstract}
Ao Xia ${ }^{1,2 *}$, Pau-Loke Show ${ }^{3}$, Alissara Reungsang ${ }^{4}$ and Timothy Walmsley ${ }^{5}$
${ }^{1}$ Key Laboratory of Low-grade Energy Utilization Technologies and Systems, Chongqing University, Ministry of Education, Chongqing, China, ${ }^{2}$ Institute of Engineering Thermophysics, School of Energy and Power Engineering, Chongqing University, Chongqing, China, ${ }^{3}$ Department of Chemical and Environment Engineering, Faculty of Science and Engineering, University of Nottingham Malaysia, Jalan Broga, Semenyih, Selangor Darul Ehsan, Malaysia, ${ }^{4}$ Research Group for Development of Microbial Hydrogen Production Process from Biomass, Department of Biotechnology, Faculty of Technology, Khon Kaen University, Khon Kaen, Thailand, ${ }^{5}$ Ahuora-Smart Energy Systems Group, School of Engineering, University of Waikato, Hamilton, New Zealand
\end{abstract}

Keywords: gaseous biofuels, anaerobic digestion, algae, pre-treatment, biorefinery, fermentation, process integration

\section{Editorial on the Research Topic}

Innovative Technology and System Integration for Gaseous Biofuels Production

Primary energy demand in the world is expected to continue to grow over the next few decades with population and economy (Sarkodie et al., 2019; Sharma et al., 2020). Excessive exploitation and utilization of fossil fuels have led to energy shortage and environmental pollution (Cheng et al., 2020). To date, many countries have the ambition to achieve carbon neutrality between 2050 and 2060. It is urgent to explore advanced and clean fuel sources for the future sustainable development and decarbonization of the society (Chiaramonti et al., 2021).

Biomass resources, such as straws, food wastes, algae, and manures, are underutilized in most parts of the world (Chew et al., 2017; Qin et al., 2018). Converting biomass feedstock to green gaseous biofuels has a great potential for the reduction of pollutant emissions and may play a significant role in future energy system (Khoo et al., 2020; Murphy and Thamsiriroj, 2011).

There are a number of existing pathways capable of producing gaseous biofuels; however, the optimal pathway is difficult to define due to technology challenges and maturity, variations in available feedstock, and the wider contexts within which a solution is implemented. For example, biogas rich in methane can be produced through anaerobic digestion (AD), which is a mature technology and has been applied worldwide in recent years. Nevertheless, the biogas production rate, the process stability, and the feedstock utilization efficiency are still not satisfactory and need to be further improved. Additionally, the treatment of liquid digestate from full-scale biogas systems may require significant energy inputs and raise environmental risks (Xia and Murphy, 2016). To achieve an efficient AD process, it is crucial to fully understand the mechanisms of the microbial conversion to propose effective enhancement strategies. An energy-efficient and environment-friendly biomass feedstock pre-treatment and hydrolysis processes would be advantageous for the access and utilization by microbes to improve biofuel production (Deng et al., 2019). Furthermore, the biomass pretreatment, biofuel production and upgrading, as well as byproducts production should be integrated and optimized to maximize the efficiency and minimize the cost of such a system. The research topic includes three original research articles and two review articles, which combine and cover various aspects of the innovation in gaseous biofuels production technologies and systems.

Lin et al. investigated the impact of hydrothermal dilute acid pre-treatment on the hydrolysis performance of grass silage. An optimal hydrothermal condition at the temperature of $140^{\circ} \mathrm{C}$ and time of 20 min was identified, with a maximum sugar yield of $0.29 \mathrm{~g} / \mathrm{g}$ volatile solid (VS). A first-order reaction model combining grass silage hydrolysis and degradation was established to successfully predict the 
production and consumption of sugars. The authors indicated that heat recovery could significantly reduce the energy requirement of hydrothermal pre-treatment process.

Uddin et al. reviewed the innovative technologies and key factors for $\mathrm{AD}$ process. The challenges and the future perspective associated with $\mathrm{AD}$ process were highlighted. The authors identified appropriate temperature and $\mathrm{pH}$, a strong inoculum to substrate ratio, good mixing, and small particle sizes are crucial to ensure an efficient $\mathrm{AD}$ process, which can provide some guidelines for the renewable gaseous biofuels production by using organic wastes as substrates.

The work of Te et al. was dedicated to the optimization of pyrolysis parameters for biochar production from banana peels. The optimal pyrolysis parameters were identified at a temperature of $356.1^{\circ} \mathrm{C}$, a residence time of $180 \mathrm{~min}$, and a heating rate of $14.7^{\circ} \mathrm{C} \mathrm{min}^{-1}$, achieving a biochar yield of 58.8 and a $\mathrm{O} / \mathrm{C}$ ratio of 0.289 . Subsequently, the optimum biochar was selected for the growth of Ipomoea aquatica. The results suggested that the highest final plant height could be achieved at a biochar dosage of $1 \%$.

Wang et al. assessed the potential of microalgae as substrates for the production of clean gaseous biofuels. The hydrogen-producing enzymes in microalgae and the hydrogen production pathways have been summarized and compared. Various bioprocess engineering and genetic engineering were reviewed for the enhancement of biohydrogen production. Also, the recent progresses in integrated biorefinery systems for hydrogen and methane co-production were discussed in detail. The study also highlighted the future trends and challenges associated with hydrogen and methane production from microalgae.

A study by Khamtib et al. used expanded clay as a supporting material for hydrogen co-fermentation of oil palm trunk hydrolysate and slaughterhouse wastewater by Thermoanaerobacterium thermosaccharolyticum KKU19 in a

\section{REFERENCES}

Cheng, B., Huang, B., Zhang, R., Chen, Y., Jiang, S., Lu, Y., et al. (2020). Bio-coal: A Renewable and Massively Producible Fuel from Lignocellulosic Biomass. Sci. Adv. 6, eaay0748. doi:10.1126/sciadv.aay0748

Chew, K. W., Yap, J. Y., Show, P. L., Suan, N. H., Juan, J. C., Ling, T. C., et al. (2017). Microalgae Biorefinery: High Value Products Perspectives. Bioresour. Technology 229, 53-62. doi:10.1016/j.biortech.2017.01.006

Chiaramonti, D., Talluri, G., Scarlat, N., and Prussi, M. (2021). The challenge of Forecasting the Role of Biofuel in EU Transport Decarbonisation at 2050: A Meta-Analysis Review of Published Scenarios. Renew. Sustainable Energ. Rev. 139, 110715. doi:10.1016/j.rser.2021.110715

Deng, Z., Xia, A., Liao, Q., Zhu, X., Huang, Y., and Fu, Q. (2019). Laccase Pretreatment of Wheat Straw: Effects of the Physicochemical Characteristics and the Kinetics of Enzymatic Hydrolysis. Biotechnol. Biofuels 12, 159. doi:10. 1186/s13068-019-1499-3

Khoo, K. S., Chew, K. W., Yew, G. Y., Leong, W. H., Chai, Y. H., Show, P. L., et al. (2020). Recent Advances in Downstream Processing of Microalgae Lipid Recovery for Biofuel Production. Bioresour. Technology 304, 122996. doi:10. 1016/j.biortech.2020.122996

Murphy, J. D., and Thamsiriroj, T. (2011). What Will Fuel Transport Systems of the Future? Mater. Today 14, 518-524. doi:10.1016/s1369-7021(11)70277-2

Qin, Z., Zhuang, Q., Cai, X., He, Y., Huang, Y., Jiang, D., et al. (2018). Biomass and Biofuels in China: Toward Bioenergy Resource Potentials and Their Impacts on fixed-bed reactor under a non-sterile condition. Long-term results demonstrated that expanded clay can effectively immobilize the microbial cells, while converting organic substrates into hydrogen. An optimal hydrogen production rate of $6.82 \mathrm{~L} / \mathrm{L}$ and a hydrogen yield of $231.99 \mathrm{ml} \mathrm{H}_{2} / \mathrm{g}$-COD were achieved at a hydraulic retention time of $6 \mathrm{~h}$. Meanwhile, the dominant soluble metabolite products were butyric and acetic acids, suggesting an efficient hydrogen fermentation process.

Collectively, these studies demonstrated a high level of scholarship and addressed a wide range of technical issues that constrain progress towards realizing gaseous biofuels in full-scale integrated production plants. We sincerely thank all authors and reviewers for their valuable contribution to the research topic. We also thank the Frontiers in Energy Research team for their support and assistance.

\section{AUTHOR CONTRIBUTIONS}

AX wrote the Editorial with contributions from PS, AR, and TW. All authors contributed to the Editorial and approved the final version.

\section{FUNDING}

This work was supported by the National Natural Science Foundation of China (No. 51876016), the Thailand Science Research and Innovation (TSRI) Senior Research Scholar (Grant No. RTA6280001), the Fundamental Research Grant Scheme, Malaysia (FRGS/1/2019/STG05/UNIM/02/2), and the New Zealand Strategic Science Investment Fund-Ahuora: Delivering sustainable industry through smart process heat decarbonization. the Environment. Renew. Sustainable Energ. Rev. 82, 2387-2400. doi:10.1016/j. rser.2017.08.073

Sarkodie, S. A., Strezov, V., Weldekidan, H., Asamoah, E. F., Owusu, P. A., and Doyi, I. N. Y. (2019). Environmental Sustainability Assessment Using Dynamic Autoregressive-Distributed Lag Simulations-Nexus between Greenhouse Gas Emissions, Biomass Energy, Food and Economic Growth. Sci. Total Environ. 668, 318-332. doi:10.1016/j.scitotenv.2019.02.432

Sharma, S., Basu, S., Shetti, N. P., and Aminabhavi, T. M. (2020). Waste-to-energy Nexus for Circular Economy and Environmental protection: Recent Trends in Hydrogen Energy. Sci. Total Environ. 713, 136633. doi:10.1016/j.scitotenv.2020.136633

Xia, A., and Murphy, J. D. (2016). Microalgal Cultivation in Treating Liquid Digestate from Biogas Systems. Trends Biotechnol. 34, 264-275. doi:10.1016/j. tibtech.2015.12.010

Conflict of Interest: The authors declare that the research was conducted in the absence of any commercial or financial relationships that could be construed as a potential conflict of interest.

Copyright (C) 2021 Xia, Show, Reungsang and Walmsley. This is an open-access article distributed under the terms of the Creative Commons Attribution License (CC $B Y)$. The use, distribution or reproduction in other forums is permitted, provided the original author(s) and the copyright owner(s) are credited and that the original publication in this journal is cited, in accordance with accepted academic practice. No use, distribution or reproduction is permitted which does not comply with these terms. 